\title{
Distribution of Cross-reactive Antigens A and B in Streptococcus mutans and Other Oral Streptococci
}

\author{
By ROY R. B. RUSSELL \\ Dental Research Unit, Royal College of Surgeons of England, Downe, \\ Orpington, Kent BR6 $7 J J$
}

(Received 6 December 1979)

\begin{abstract}
A collection of strains representing the various common species of oral streptococci was examined for the presence of antigens cross-reacting with antigens A and B from Streptococcus mutans serotype $c$. Antigens cross-reacting with A were found only in $S$. mutans serotype $b$. Antigens cross-reacting with B were found in $S$. mutans serotypes $a, c, d, e, f$ and $g$ and also in strains of $S$. sanguis. All antigens cross-reacting with B were precipitated by antiserum to human heart tissue.
\end{abstract}

\section{INTRODUCTION}

Recent advances in the taxonomy of the 'viridans' group of streptococci commonly found in the oral cavity have resulted in general agreement on the boundaries between the species Streptococcus salivarius, $S$. mutans, $S$. milleri, S. sanguis and $S$. mitior (also called $S$. mitis), though some differences of opinion remain concerning the relationship between the last two (Colman, 1976; Facklam, 1977; Hardie \& Marsh, 1978). The taxonomic divisions are based primarily on physiological characteristics, supported in some cases by studies of cell wall composition or DNA homology (Colman \& Williams, 1972; Coykendall $\&$ Munzenmaier, 1978). Studies on the serology of the viridans streptococci, however, have demonstrated extensive cross-reactions between species, though the cross-reacting antigens have not generally been identified (Colman, 1976; Colman \& Williams, 1972; Facklam, 1977; Hardie \& Bowden, 1976; Hardie \& Marsh, 1978).

The antigenic structure of $S$. mutans is of particular interest because of the role played by this organism in the initiation of dental caries and the fact that vaccines based on $S$. mutans can protect experimental animals against this disease (Bowen, 1976). The polysaccharide antigens of $S$. mutans, on which the serotyping system is based, have been extensively studied (Linzer et al., 1976), but little is yet known about the protein antigens of the species (Bratthall \& Pettersson, 1976). Recent reports described the purification of two wall-associated protein antigens of $S$. mutans serotype $c$ : these antigens, designated $\mathrm{A}$ and $\mathrm{B}$, had molecular weights of 29000 and 190000, respectively (Russell, 1979a,b). Antigen B was of particular interest because it showed antigenic cross-reactivity with human heart tissue (Hughes, 1979; Hughes et al., 1980; Russell, 1979 b). Antibody responses to both antigens $\mathrm{A}$ and $\mathrm{B}$ were found in monkeys immunized against dental caries (Cohen et al., 1979), though the role they play in protection has yet to be elucidated. The present communication describes an investigation into the distribution of these antigens in the various serotypes of $S$. mutans and in representatives of other streptococcal species. 


\section{METHODS}

Organisms. The following strains of Streptococcus mutans were used: serotype $a-$ AHT, OMZ61, NIDR 3720; serotype $b$ - FA1, OMZ51, OMZ71; serotype $c$ - Ingbritt, GS5, NCTC 10449; serotype $d$ - OMZ176, OIHI, B13; serotype $e$ - P4, NCTC 10923, At 10; serotype $f$-SE11, 151, 4177; serotype $g-\mathrm{K} 1$, OMZ65, TH62. The sources of these strains were described previously (Russell, 1976) with the exception of strain AHT which was obtained from D. Bratthall and confirmed as type $a$ (Russell, 1979d). Streptococci other than $S$. mutans were kindly provided by G. Colman of this laboratory. Streptococcus sanguis strains are listed in Table 2. Other strains used were $S$. mitior FW9, FW63 and FW75, S. milleri IS8, IS57, 7180, S198, FW702 and OG7331, and $S$. salivarius FW43 and BU104.

Media and culture conditions. Bacteria were grown in Todd-Hewitt broth (Oxoid) for $20 \mathrm{~h}$ at $37^{\circ} \mathrm{C}$.

Extraction methods. Bacteria from a culture grown for $20 \mathrm{~h} \mathrm{in} 20 \mathrm{ml}$ Todd-Hewitt broth were collected by centrifugation. For acid extraction, the pellet was heated with $50 \mu \mathrm{l} 0.2 \mathrm{M}-\mathrm{HCl}$ at $100{ }^{\circ} \mathrm{C}$ for $10 \mathrm{~min}$. For autoclave extraction, the pellet was heated with $50 \mu 10.9 \%(\mathrm{w} / \mathrm{v}) \mathrm{NaCl}$ at $121{ }^{\circ} \mathrm{C}$ for $15 \mathrm{~min}$. For extraction by mutanolysin, the pellet was suspended in $0.01 \mathrm{M}$-Tris/maleate/ $\mathrm{NaOH}$ buffer $(\mathrm{pH} 7 \cdot 0)$ containing mutanolysin M-1 enzyme (Yokogawa et al., 1975; $200 \mu \mathrm{g} \mathrm{ml}^{-1}$ ) and incubated for $3 \mathrm{~h}$ at $37^{\circ} \mathrm{C}$. The extracted slurries were used for immunodiffusion without further centrifugation. Mutanolysin was generously provided by M. Yokogawa, Dainippon Pharmaceutical Company, Japan.

Preparation of antisera. Typing sera were prepared in rabbits by a course of intravenous injections of heat-killed cells of $S$. mutans as described by Bratthall (1970). The production of antiserum to pure antigens $\mathrm{A}$ and $\mathrm{B}$ has been described (Russell, $1979 a, b$ ) and rabbit antiserum to human heart tissue was kindly provided by Dr M. Hughes, Wellcome Research Laboratories (Hughes, 1979; Hughes et al., 1980).

Serological methods. Agglutination of broth cultures grown for $16 \mathrm{~h}$ was tested by mixing a drop of culture with $5 \mu \mathrm{l}$ antiserum on a microscope slide and rocking it gently. Agglutination, when it occurred, was apparent within $5 \mathrm{~min}$. Immunodiffusion was performed in $1 \%(\mathrm{w} / \mathrm{v})$ agarose in $0.05 \mathrm{M}-\mathrm{Tris} / \mathrm{HCl}$ buffer (pH 7.5) on glass slides. Samples of $20 \mu \mathrm{l}$ antigen preparation or antiserum were placed in $4 \mathrm{~mm}$ diameter wells $4 \mathrm{~mm}$ apart. Slides were dried, washed in saline and the immunoprecipitates were stained with Coomassie blue as described by Axelsen et al. (1973).

Preparations of antigens. Lipoteichoic acid and serotype polysaccharides were extracted from bacteria with hot aqueous phenol (Westphal \& Jann, 1965). The antigens were then purified by gel filtration on a column of Sepharose 6B followed by ion-exchange chromatography on DEAE-Sephadex, essentially as described by Linzer et al. (1976). Lipoteichoic acid was prepared from strain Ingbritt, and serotype polysaccharides from AHT, FA1, Ingbritt and $\mathrm{K} 1$.

\section{RESULTS}

\section{Antibodies in typing sera}

Antigens A and B were purified from $S$. mutans strain Ingbritt (serotype $c$ ) and antigenically identical proteins were detected in strains of serotypes $e$ and $f$; serotype $b$ strains contained an antigen cross-reacting with $\mathrm{A}$ while strains of serotypes $d$ and $g$ contained antigens cross-reacting with B (Russell, 1979 $a, b$ ). The occurrence of these antigens in more than one serotype suggested that antibodies to antigens A or B might be a cause of lack of specificity of typing sera. A collection of sera prepared in this laboratory for serotyping purposes was therefore examined by immunodiffusion for the presence of antibodies to a number of defined antigens. All the typing sera were prepared by intravenous injection of rabbits with heat-killed whole cells and 10 out of 12 sera had the desired anti-polysaccharide antibodies, though four were non-specific due to the presence of antibodies to lipoteichoic acid (Table 1). Precipitin lines of polysaccharide or lipoteichoic acid appeared sooner and were stronger than those containing protein antigens when slides were viewed on a darkground lightbox, but slides stained with Coomassie blue clearly revealed the presence of precipitates to antigen $B$ in six of the sera and to antigen A in three sera (Table 1). Figure 1 shows the reactions of antiserum against strain GS5 with extracts from representatives from all seven serotypes. 


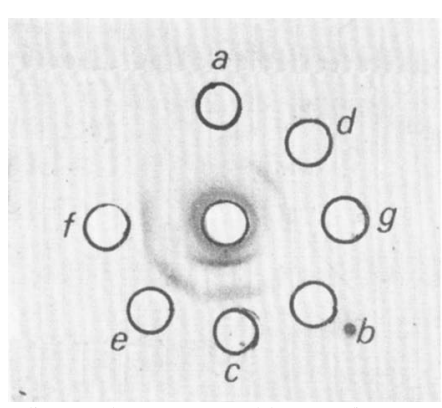

Fig. 1

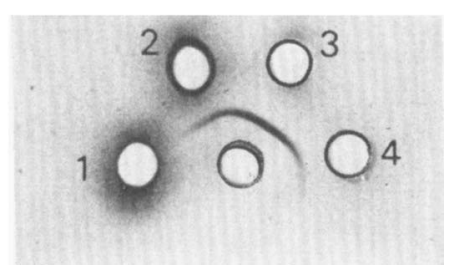

Fig. 2

Fig. 1. Immunodiffusion of antiserum raised against whole cells of strain GS5 (centre well) and autoclave extracts of representatives of the different $S$. mutans serotypes. The line close to the antiserum well is due to antibody to serotype $c$ polysaccharide, while the other lines are due to antibody to antigen $\mathbf{B}$.

Fig. 2. Immunodiffusion of antisera raised against SDS-extracted cells of different $S$. mutans serotypes and pure antigen B from strain Ingbritt. 1, anti-FAl $(b) ; 2$, anti-OMZ61 $(a) ; 3$, antiIngbritt $(c) ; 4$, anti-K1 $(g)$.

\section{Table 1. Antibodies present in sera prepared for serotyping $S$. mutans}

Each serum came from a different rabbit immunized with heat-killed $S$. mutans. Sera were tested by two-dimensional immunodiffusion against four purified antigens. The polysaccharide antigen used was that prepared from a strain of the same serotype as the immunizing strain.

$$
\underset{\text { Immunizing }}{\text { Imain }}
$$

AHT

OMZ61

FA1

FA1

FAl

GS5

Ingbritt

Ingbritt

Ingbritt

K1

$\mathrm{K} 1$

K1
Antigen*

Serotype
$\begin{aligned} & a \\ & a \\ & b \\ & b \\ & b \\ & c \\ & c \\ & c \\ & c \\ & g \\ & g \\ & g\end{aligned}$

$\begin{array}{cccc}\text { PS } & \text { LTA } & \text { A } & \text { B } \\ + & - & - & - \\ - & - & - & + \\ + & + & + & - \\ + & + & + & - \\ + & - & - & - \\ + & - & - & + \\ + & - & + & + \\ - & - & - & + \\ + & + & - & + \\ + & + & - & + \\ + & - & - & - \\ + & - & - & -\end{array}$

* PS, Serotype-specific polysaccharide; LTA, lipoteichoic acid.

Presence of antigen $B$ in serotype a

Evidence from the typing sera indicated that antiserum raised against the serotype $a$ strain OMZ61 reacted with antigen B, although no cross-reacting antigen had previously been detected in culture filtrates, autoclave or acid extracts of strains of this serotype (Russell, 1979b). Antigen B from strain Ingbritt was originally characterized as an antigen which remained on the bacteria even after boiling in sodium dodecyl sulphate (SDS) (Russell, 1979 $b$ ). That an analogous antigen existed in serotype $a$ was demonstrated by using SDS-extracted cells of OMZ61 to immunize a rabbit. The resultant antiserum precipitated antigen B (Fig. 2). The same approach failed to detect any such antigen in strain FA1 (serotype $b$ ). Further evidence for the presence of antigen B in serotype $a$ strains was provided by the observation of the slide agglutination of serotype $a$ strains by antiserum raised against pure antigen $B$ (Table 2). 
Table 2. Detection of antigens reacting with antiserum to antigen $B$

\begin{tabular}{|c|c|c|c|c|}
\hline & & & tection meth & \\
\hline Stra & & Agglutination & $\begin{array}{c}\text { Autoclave } \\
\text { extract }\end{array}$ & $\begin{array}{c}\text { Mutanolysin } \\
\text { extract }\end{array}$ \\
\hline S. mutans* & & & & \\
\hline Serotype & $a$ & + & - & + \\
\hline & $b$ & - & - & - \\
\hline & $c$ & + & + & + \\
\hline & $d$ & $x \dagger$ & + & + \\
\hline & $e$ & + & + & + \\
\hline & $f$ & + & + & + \\
\hline & $g$ & $x \dagger$ & + & + \\
\hline S. sanguis & & & & \\
\hline Type I & MWK & - & - & + \\
\hline & NCTC 7865 & + & - & + \\
\hline & NCTC 7869 & - & - & + \\
\hline & NCTC 10231 & - & - & - \\
\hline Type II & S159 & - & + & + \\
\hline & Bu174 & - & + & + \\
\hline & NCTC 7864 & - & + & + \\
\hline
\end{tabular}

\section{Extraction of antigen $B$ with mutanolysin}

The above results indicated that strains of serotype $a$ possessed an antigen resembling antigen $\mathrm{B}$, but that it was not as readily released as the corresponding antigen from other serotypes. An alternative method for release of antigen was therefore sought. Mutanolysin is an enzyme from Streptomyces globisporus which has been reported to lyse all serotypes of $S$. mutans and other streptococci (Hamada et al., 1978). We confirmed these observations and found that digestion with mutanolysin efficiently released antigen B from all strains known to contain it, including those of serotype $a$ (Table 2). No cross-reacting antigen was released from any of the three serotype $b$ strains.

\section{Antigens in other streptococci}

The methods found suitable for detecting antigen in the $S$. mutans strains were applied to a collection of representative strains of the other streptococci commonly found in the mouth. An antigen cross-reacting with B was detected in six out of seven strains of $S$. sanguis (Table 2). No such antigen was found in the strains of $S$. mitior, $S$. milleri or $S$. salivarius. The presence of an antigen cross-reacting with antigen A from strain Ingbritt was previously reported in serotype $b$ strains (Russell, 1979a). The present survey confirmed this finding, but failed to detect a cross-reacting antigen in any of the other strains examined.

\section{Heart cross-reactivity}

Antigen B from S. mutans strain Ingbritt has been shown to be precipitated by rabbit antiserum raised against human heart tissue (Hughes, 1979; Hughes et al., 1980; Russell, $1979 \mathrm{~b}$ ). In immunodiffusion the same anti-heart serum reacted with all those extracts of $S$. mutans and S. sanguis which contained antigen cross-reacting with antigen B.

\section{DISCUSSION}

The antigens involved in cross-reactivity between oral streptococci have not been identified. Lipoteichoic acid and dextran are believed to be responsible for some cross- 
reactions (Bratthall, 1969; Chorpenning et al., 1975), and Hardie \& Bowden (1976) presented preliminary evidence that a protein antigen was common to $S$. mutans and $S$. sanguis. I recently characterized antigen B of $S$. mutans strain Ingbritt as a wall-associated protein with an apparent molecular weight of 190000 and the present report shows that six of the seven serotypes of $S$. mutans contain this or a closely similar antigen, as do strains of $S$. sanguis. It is perhaps surprising that $S$. mutans serotype $b$ strains lacked the antigen as serotypes $b$ and $c$ are closely related genetically (Coykendall, 1974) and have already been shown to have antigenically cross-reacting glucosyltransferase (Russell, 1979c) and antigen A (Russell, 1979a). The possibility remains that a cross-reacting antigen might be discovered if a wider range of growth conditions and extraction methods were introduced.

Cross-reacting antigen B was detected in strains of both $S$. sanguis type I and S. sanguis type II but not in strains of $S$. mitior. Some authors have suggested $S$. sanguis type II strains should be classified as $S$. mitior from which they differ only in the ability to synthesize a water-soluble glucan (Coykendall \& Munzenmaier, 1978), and while this might suggest that the antigen common to all the $S$. sanguis strains is glucosyltransferase, clear evidence has been presented that glucosyltransferase and antigen B from $S$. mutans strain Ingbritt are distinct entities (Russell, 1979b).

The most widely employed technique for producing sera for typing $S$. mutans involves intravenous injection of whole bacteria into rabbits and it is generally recognized that one or more absorption steps are needed to produce serotype-specific sera. The results presented in Table 1 indicate that antigens $A$ and $B$ may frequently be the causes of the non-specificity of sera.

A knowledge of antigenic determinants which may be shared between species is essential in any studies in which attempts are made to assess levels of antibody to a particular organism. For instance, numerous attempts have been made to correlate levels of antibody to $S$. mutans with caries experience, but it is now clear that if whole bacteria are used in immunoassay procedures not only specific antibody will be detected, but also antibody to such non-specific antigens as lipoteichoic acid (Decker et al., 1972; Markham et al., 1973) and antigen $B$.

Characterization of the antigens involved in heart cross-reactivity and their distribution is also needed for appreciation of the hazards involved in the development of streptococcal vaccines. Furthermore, a knowledge of the antigenic relationships of different oral streptococci may help provide information on the mechanism by which immunity to dental caries is obtained, as it is clear that immunization with $S$. mutans may induce antibodies capable of reacting with other species.

I am grateful to D. Bratthall for supplying S. mutans AHT, to G. Colman for providing many bacterial strains and some of the typing sera, to $M$. Hughes for the anti-heart serum and to M. Yokogawa for his generous gift of mutanolysin.

\section{REFERENCES}

Axelsen, N. H., Kroll, J. \& Weeke, B. (1973). $A$ Manual of Quantitative Immunoelectrophoresis. Oslo: Universitatetsforlaget.

Bowen, W. H. (1976). Relevance of caries vaccine investigations in rodents, primates and humans: critical assessment. In Immunological Aspects of Dental Caries, pp. 11-20. Edited by W. H. Bowen, R. J. Genco \& T. C. O'Brien. London: Information Retrieval Limited.

Bratthall, D. (1969). Immunodiffusion studies on the serological specificity of streptococci resembling Streptococcus mutans. Odontologisk revy $\mathbf{2 0}$, 231-243.
Bratthall, D. (1970). Demonstration of five serological groups of streptococcal strains resembling Streptococcus mutans. Odontologisk revy 21, 143-152.

Bratthall, D. \& Pettersson, B.-M. (1976). Common and unique antigens of Streptococcus mutans. Journal of Dental Research 55 (Special Issue A), A60-A64.

Chorpenning, F. W., Cooper, H. R. \& Rosen, S. (1975), Cross-reactions of Streptococcus mutans due to cell wall teichoic acid. Infection and Immunity 12, 586-591.

Cohen, B., Colman, G. \& Russell, R. R. B. (1979). 
Immunization against dental caries: further studies. British Dental Journal 147, 9-14.

Colman, G. (1976). The viridans streptococci. In Selected Topics in Clinical Bacteriology, pp. 179198. Edited by J. de Louvois. London: Bailliere Tindall.

Colman, G. \& Williams, R. E. O. (1972). Taxonomy of some human viridans streptococci. In Streptococci and Streptococcal Diseases, pp. 281-298. Edited by L. W. Wannamaker \& J. M. Matsen. New York \& London: Academic Press.

Coykendall, A. L. (1974). Four types of Streptococcus mutans based on their genetic, antigenic and biochemical characteristics. Journal of General Microbiology 83, 327-338.

Coykendall, A. L. \& Munzenmaier, A. J. (1978). Deoxyribonucleic acid base sequence studies on glucan-producing and glucan-negative strains of Streptococcus mitior. International Journal of Systematic Bacteriology 28, 511-515.

Decker, G. P., Chorpenning, F. W. \& Frederick, G. T. (1972). Naturally occurring antibodies to bacillary teichoic acids. Journal of Immunology 108, 214-222.

FACKLAM, R. R. (1977). Physiological differentiation of viridans streptococci. Journal of Clinical Microbiology 5, 184-201.

hamada, S. Tori, M., Kotani, S., Masuda, N., Ooshima, T., Yokogawa, K. \& Kawata, S. (1978). Lysis of Streptococcus mutans cells with mutanolysin, a lytic enzyme prepared from a culture liquor of Streptomyces globisporus 1829. Archives of Oral Biology 23, 543-549.

Hardie, J. M. \& Bowden, G. H. (1976). Some serological cross-reactions between Streptococcus mutans, $S$. sanguis and other dental plaque streptococci. Journal of Dental Research $\mathbf{5 5}$ (Special Issue C), C50-C58.

HARDie, J. M. \& Marsh, P. D. (1978). Streptococci and the human oral flora. In Streptococci, pp. 157-206. Edited by F. A. Skinner \& L. B. Quesnel. London: Academic Press.

HugHes, M. (1979). Cross-reactions of Streptococcus mutans with heart-tissue antigens. In Pathogenic Streptococci, pp. 222-224. Edited by M. T. Parker. Chertsey: Reedbooks.

Hughes, M., MacHardy, S. M., Sheppard, A. J. \& Woods, N. C. (1980). Evidence for an immunological relationship between Streptococcus mutans and human cardiac tissue. Infection and Immunity 27, 576-588.

Linzer, R., Gill, K. \& Slade, H. D. (1976). Chemical composition of Streptococcus mutans type $c$ antigen: comparison to type $a, b$ and $d$ antigens. Journal of Dental Research 55 (Special Issue A), A109-A115.

Markham, J. L., Knox, K. W. \& Schamschula, R. G. (1973). Antibodies to teichoic acids in man. Archives of Oral Biology 18, 313-319.

Russell, R. R. B. (1976). Classification of Streptococcus mutans strains by SDS gel electrophoresis. Microbios Letters 2, 55-59.

Russell, R. R. B. (1979 a). Cell-wall protein antigens of Streptococcus mutans. In Pathogenic Streptococci, pp. 221-222. Edited by M. T. Parker. Chertsey: Reedbooks.

Russell, R. R. B. (1979 b). Wall-associated protein antigens of Streptococcus mutans. Journal of General Microbiology 114, 109-115.

RusSELl, R. R. B. $(1979 c)$. Glycosyltransferases of Streptococcus mutans strain Ingbritt. Microbios 23, 135-146.

Russell, R. R. B. $(1979 d)$. Comparison of Streptococcus mutans AHT with strains of serotypes $a$ and $g$ by biochemical and electrophoretic methods. Archives of Oral Biology 24, 617-619.

WestPhal, O. \& JANN, K. (1965). Bacterial lipopolysaccharide extraction with phenol-water and further applications of the procedure. Methods in Carbohydrate Chemistry 5, 83-91.

Yokogawa, K., Kawata, S., Takemura, T. \& Yoshimura, Y. (1975). Purification and properties of lytic enzymes from Streptomyces globisporus 1829. Agricultural and Biological Chemistry 39, 1533-1543. 